\section{Hungary's 'reforms' are threatening basic science}

SIR - Your News story “Hungary's science academy slammed as 'obsolete'" (Nature 441, 1034-1035; 2006) rightly highlights the often-hierarchical and somewhat oldfashioned organization of the academic research scene in Hungary. A reform that would provide opportunities to successful Hungarian researchers working all over the world is indeed needed. However, by stating that "the Hungarian government... is trying to reform the country's research system and attract more high-profile scientists", your News story is too kind.

What the government means by 'reform' is budget cuts and restructuring of the increasingly limited resources provided for research. For example, the government did not hide its plans to privatize the academyowned research infrastructure, as it was hoping to generate cash to deal with its own dire financial situation.

It is not obvious to us that selling some of its most valuable properties would help the academy to renew; on the contrary. Our concern is that a reform process driven by economic pressure would, instead, sacrifice the academy and basic research in Hungary on the altar of questionable economics. This is far from strengthening Hungarian science. We think most Hungarian scientists would agree with us, on the basis of the open letter to the prime minister, signed by some 2,500 scientists, begging the government not to cut the already lean budget allocated to basic scientific research even further (see www. petitiononline.com/otka).

Sadly, it seems that, as a central strategy of its 'reform process', the Hungarian government is continuing to attack basic science. It uses the populist argument that Hungary is too small and too poor to 'waste' taxpayers' money on basic-research projects for which a speedy return on investment cannot be immediately identified. Hence it withdraws support from basic science and reallocates it to applied research, or research that is able to produce marketable products in a relatively short period of time.

We believe that this concept puts the basic-research network in Hungary (under the umbrella of the Academy of Sciences) into serious danger. With its short-sighted outlook, the government does not realize that its 'reform' activities undermine the development of a healthy innovation chain, and drown the personal creativity that has been an asset and a source of pride for Hungarian science.

Since it was founded in 1825 , the primary mission of the academy has been to keep an eye on the cultural and scientific horizon in service of the nation's long-term interests. No government agenda formulated under economic pressure should compromise this mission. Zsuzsanna Izsvák, Zoltán Ivics, Lajos Mátés Max Delbrück Center for Molecular Medicine, Robert Rösslestraße 10, D-13092 Berlin, Germany

\section{Challenge of choosing right level of microarray detail}

SIR - Your Technology Feature on microarray databases and standards, "Share and share alike" (Nature 442, 1069; 2006), is incorrect to state that the National Center for Biotechnology Information's Gene Expression Omnibus (GEO) database is not compliant with MIAME (minimum information about a microarray experiment) standards.

GEO is in fact MIAME-compliant, as it fully supports capture of all data elements defined by MIAME and encourages use of the MIAME checklist in determining what information to submit about an experiment.

Biological context is essential to interpret the underlying data in functional-genomic databases such as GEO. The challenge lies in choosing the right level of detail to require: too little and the database will not be robust enough to meet scientific demands; too much and scientists may be discouraged from submitting, or may inadvertently enter the information inaccurately. The appropriate level of biological context can vary widely between experiments, is difficult to standardize and may change over time. The level of effort a submitter is willing or able to expend may also change with shifting data-submission requirements by journals and funding agencies.

The National Center for Biotechnology Information began GEO in 2000 with a requirement for a minimal level of detail. As the field developed, we encouraged submitters to provide more specific details and modified the database design to include provisions for all MIAME data elements. The result of this incremental approach has been positive, with the growth rate and quality of GEO submissions rising rapidly over time.

Finding and maintaining the optimal balance between complexity and usefulness is challenging, as is providing appropriate tools and resources that evolve with changes in the science and social environment. GEO will continue to monitor the needs of the community and work with the Microarray Gene Expression Data Society and the European Bioinformatics Institute (which produces the ArrayExpress database), as we all seek this balance.

\section{Ron Edgar}

Gene Expression Group/National Center for Biotechnology Information, National Library of Medicine, National Institutes of Health, 45 Center Drive, MSC6511, Bethesda, Maryland 20892-6511, USA

\section{Funders with money to spare could just pay more}

SIR - A recent Naturejobs Prospects article (Nature 442, 841; 2006) notes that Research Councils UK (RCUK) has recognized that postdoctoral salaries are insufficient, leading to problems in attracting and retaining postdoctoral staff. It would make sense for RCUK to address the problem globally, for example by increasing the baseline salaries of postdoctoral staff, or by giving principal investigators greater flexibility to set salary levels at the time of appointment.

Rather than taking such a global course, RCUK has instead offered to consider applications from principal investigators for 'enhancements' to individual postdoctoral salaries in strategically desirable scientific disciplines. According to the Prospects article, the organization is now complaining that it has not received enough applications for these top-up funds. RCUK should realize that this is less likely to be because principal investigators are unaware of its scheme than because of the additional administration and bureaucracy involved in providing individual justifications.

Shantenu Jha

Centre for Computational Science, University College London, 20 Gordon Street, London WC1H OAJ, UK

\section{Piltdown wasn't cricket but does the hobbit ring true?}

SIR - I was surprised that you managed to discuss palaeoanthropological controversies in your Editorial "Rude palaeoanthropology" (Nature 442, 957-958; 2006 ) without mentioning Piltdown man. The discovery of this 'missing link' in 1912 caused a stir, during the period between the Neanderthal and Australopithecus africanus disputes that you mention. Debate about it continued until it was exposed as a hoax in 1953.

Although I'm not suggesting that Homo floresiensis is a fake, the behaviour of the participants and those reporting on them could be drawn from that scene of palaeoanthropological bad behaviour in Sussex. All that seems to be missing in Indonesia is a cricket bat like the one carved from bone and found at the Piltdown site, which failed to alert its finders to the fact that this was a hoax.

So let's look forward to a season of digging to resolve the issues at hand. We could hope, perhaps, for the discovery of artefacts, tools or jewellery - rings, for example? — that might help to clarify the position of the hobbit in prehistory.

Simon L. Goodman

Friedrich Ebertstraße 102a,

64347 Griesheim, Germany 